\title{
Serum magnesium is inversely associated with coronary artery calcification in the Genetics of Atherosclerotic Disease (GEA) study
}

Rosalinda Posadas-Sánchez ${ }^{1 *}$ (D) Carlos Posadas-Romero ${ }^{1}$, Guillermo Cardoso-Saldaña ${ }^{1}$, Gillberto Vargas-Alarcón ${ }^{2}$, María Teresa Villarreal-Molina ${ }^{3}$, Nonanzit Pérez-Hernández², José Manuel Rodríguez-Pérez², Aida Medina-Urrutia', Esteban Jorge-Galarza ${ }^{1}$, Juan Gabriel Juárez-Rojas ${ }^{1}$ and Margarita Torres-Tamayo ${ }^{1}$

\begin{abstract}
Background: Serum magnesium is inversely associated to coronary artery calcification (CAC) in patients with chronic kidney disease. There is little information on this association in a general healthy population.

Objective: The aim of this study was to examine the cross-sectional association of serum magnesium levels with CAC.

Methods: We included 1276 Mexican-mestizo subjects (50\% women), aged 30-75 years, free of symptomatic cardiovascular disease. CAC was quantified by multidetector computed tomography using the method described by Agatston. Cross-sectional associations of serum magnesium with cardiometabolic factors and subclinical atherosclerosis defined as a CAC score $>0$, were examined in logistic regression models adjusted for age, sex, education, smoking status, body mass index, systolic blood pressure, physical activity, elevated abdominal visceral tissue, fasting insulin and glucose, alcohol consumption, menopausal status (women only), low (LDL-C) and high density lipoprotein cholesterol (HDL-C), triglycerides, diuretic use, type 2 diabetes mellitus (DM2), and family history of DM2.
\end{abstract}

Results: After full adjustment, subjects in the highest quartile of serum magnesium had $48 \%$ lower odds of hypertension $(p=0.028), 69 \%$ lower odds of DM2 $(p=0.003)$, and $42 \%$ lower odds of CAC score $>0(p=0.016)$ compared to those with the lowest serum magnesium. The analyses also showed that a $0.17 \mathrm{mg} / \mathrm{dL}$ (1SD) increment in serum magnesium was independently associated with $16 \%$ lower CAC (OR 0.84, 95 \% Cl 0.724-0.986).

Conclusions: In a sample of Mexican-mestizo subjects, low serum magnesium was independently associated to higher prevalence not only of hypertension and DM2, but also to coronary artery calcification, which is a marker of atherosclerosis and a predictor of cardiovascular morbidity and mortality.

Keywords: Serum magnesium, Coronary artery calcification, Subclinical atherosclerosis

\footnotetext{
* Correspondence: rossy_posadas_s@yahoo.it

${ }^{1}$ Departamento de Endocrinología, Instituto Nacional de Cardiología Ignacio

Chávez, Juan Badiano 1, Sección XVI, Mexico City 14080, Mexico

Full list of author information is available at the end of the article
} 


\section{Introduction}

Magnesium plays an important role in many biochemical processes including all ATP transfer reactions. Magnesium is essential for insulin release by pancreatic $\beta$-cells, and is also and important second messenger for insulin action [1, 2]. Cross-sectional [3] and longitudinal studies $[4,5]$ have found a significant inverse association between serum magnesium and DM2, insulin resistance and inflammation. Moreover, magnesium is a natural calcium antagonist [6] and modulates vasomotor tone, blood pressure, and peripheral blood flow $[7,8]$. In prospective studies, serum magnesium levels have been inversely associated with the incidence of hypertension [9] and coronary heart disease (CHD) [10]. Increased carotid intima-media thickness (CIMT) and coronary artery calcification (CAC) are both markers of subclinical atherosclerosis, and are also predictors of cardiovascular disease (CVD) morbidity and mortality independently of traditional CVD risk factors [11-13]. Inverse associations between serum magnesium and CIMT have been reported [3, 14]. However, conflicting results have been found in the two studies investigating the association of dietary magnesium and CAC $[15,16]$. Moreover, a negative association between serum magnesium and vascular calcification has been observed in patients with chronic kidney disease [17]. The only observational study that has examined this association in a population-based study reported that low serum magnesium level is associated with CAC in Koreans subjects [18]. However, it is known that CAC prevalence and amount are heavily influenced by ethnicity $[19,20]$. Therefore, in the present study we assessed the cross-sectional association of serum magnesium concentrations with coronary artery calcification in Mexican-mestizo subjects with no family history of premature CHD and asymptomatic for CVD.

\section{Methods}

\section{Study population}

The study population included participants of the Genetics of Atherosclerotic Disease (GEA) study. The GEA study was designed to examine the genomic bases of CHD and assess relationships between traditional and emerging risk factors with clinical and subclinical atherosclerotic vascular diseases in an adult Mexican-mestizo population [21]. Briefly, a convenience sample of $1200 \mathrm{CHD}$ patients and 1500 control subjects aged 30-75 years was recruited from residents in Mexico City. Patients with established premature CHD were selected from the outpatient clinic of the National Institute of Cardiology. Volunteer control participants with a negative family history of premature CHD and no personal history of cardiovascular disease were recruited from blood bank donors, and through brochures posted in Social Services centers. Coronary patients and control subjects with a history of renal, liver, thyroid, or malignant disease, as well as those on treatment with corticosteroids, were excluded. The GEA study was approved by the Institutional Review Board of the National Institute of Cardiology and conducted according to the Declaration of Helsinki. Written informed consent was obtained from all participants.

This study is a cross-sectional analysis of the baseline measurements of 1500 control subjects included in the GEA study. The participants answered structured questionnaires that provide detailed information regarding family history, demographics, diet, physical activity, medications, smoking, and alcohol intake. We excluded all subjects with missing CAC $(n=25)$, missing physical activity data $(n=111)$, missing dietary data $(n=45)$, missing insulin $(n=1)$ and magnesium sampling $(n=42)$. The final study population included in the analysis comprised 1276 subjects. Systolic and diastolic blood pressures were measured after rest for at least $10 \mathrm{~min}$, and the average of the second and third measurements was recorded for analyses. Hypertension was defined as systolic blood pressure $\geq 140 \mathrm{mmHg}$ or diastolic blood pressure $\geq 90$ $\mathrm{mmHg}$ or the current use of antihypertensive medication. Height, weight, and waist circumference were measured and BMI was calculated as weight in kilograms divided by height in meters squared. The metabolic syndrome (MS) was defined using the criteria from the American Heart Association/National Heart, Lung, and Blood Institute scientific statement on the MS [22], except for central obesity that was considered when waist circumference was $>90 \mathrm{~cm}$ in men and $>80 \mathrm{~cm}$ in women [23]. Type 2 diabetes mellitus (DM2) was defined by the American Diabetes Association criteria [24], reported glucose-lowering treatment or previous DM2 diagnosis by a physician. Family history of DM2 was defined as either mother or father having DM2. Insulin resistance was estimated using the homeostasis model assessment (HOMA-IR). Insulin resistance was defined as HOMA-IR values $\geq 75$ th percentile (3.66 in women and 3.38 in men). These cutoff points were obtained from a GEA study sample of 131 men and 185 women without obesity and with normal of blood pressure, fasting glucose and lipids measurements.

\section{Biochemical analyses}

Venous blood samples were collected from subjects after a 12 h fast. Plasma glucose, total cholesterol, triglycerides, HDL-C, apolipoprotein A (apo A), apolipoprotein B (apo B), creatinine, uric acid, aspartate aminotransferase (AST), and alanine aminotransferase (ALT), were measured in fresh samples, using standardized enzymatic procedures in a Hitachi 902 analyzer (Hitachi Ltd,Tokio, Japan). 
Accuracy and precision of lipid measurements in our laboratory are under periodic surveillance by the Centers for Disease Control and Prevention service (Atlanta, GA, USA). LDL-C was estimated using the DeLong et al. formula [25]. Total high-sensitivity C-reactive protein (hsCRP) levels were determined by immunonephelometry on a BN Pro Spec nephelometer (Dade Behring Marburg $\mathrm{GmbH}$, Germany). Interassay coefficient of variation (CV) values were $<6 \%$ for all of these assays. Serum total adiponectin was determined by ELISA (R\&D Systems, Minneapolis, USA) Quantine kit. The intra- and interassay CV were $<10 \%$. Plasma insulin concentrations were determined by a radioimmunoassay (Millipore; RIA Kit, Cat. No. HI-14 K, MO, USA) the intra- and interassay $\mathrm{CV}$ values were 2.1 and $6.8 \%$, respectively. Serum magnesium levels were measured by using the direct xylidyl blue complex method in a COBAS C311 automated chemistry analyzer (Roche diagnotics $\mathrm{GmbH}$, Germany). The intra and interassay coefficient of variation were $\leq 1.0 \%$.

\section{Computed tomography study}

Visceral adipose tissue (VAT), subcutaneous fat, liver and spleen attenuation, and coronary artery calcium were quantified by computed tomography in each participant. Computed tomography of the chest and abdomen were performed using a 64-channel multidetector helical computed tomography system (Somatom Cardiac Sensation, 64, Forcheim, Germany) and interpreted by experienced radiologists. Scans were read to assess and quantify the following: i) total abdominal, subcutaneous, and VAT areas as described by Kvist et al. [26]; ii) liver to spleen attenuation ratio (L:SAR) as described by Longo et al. [27]; and iii) CAC score using the Agatston method [28]. Subclinical atherosclerosis was defined as the presence of a CAC score $>0.0$ and hepatic steatosis as $\mathrm{L}: \mathrm{SAR} \leq 1.0$ [29].

\section{Data analysis}

Data are expressed as mean \pm S.D., median [interquartile range] for continuous variables, or as proportions for categorical variables. Serum magnesium concentrations were categorized by quartile distribution with the lowest quartile serving as the reference. Differences across quartiles were assessed with ANOVA or Kruskal-Wallis test for continuous variables, and Chi square test for categorical variables. Multivariate logistic regression analysis was used to evaluate the association between each S.D. increase in serum magnesium concentrations with coronary risk factors and CAC. For coronary risk factors, the forced-entry logistic regression analyses were adjusted for age, sex, education, smoking status, elevated abdominal visceral adipose tissue, body mass index, systolic blood pressure, low and high density lipoprotein cholesterol, triglycerides, fasting insulin and glucose, physical activity, alcohol consumption, menopausal status (women only) and diuretic use. For CAC, three forced-entry logistic regression models were constructed: an unadjusted model; a model adjusted for age, sex, education, smoking status, body mass index, systolic blood pressure, and physical activity (model 1); a regression model further adjusted for elevated abdominal visceral adipose tissue, fasting insulin and glucose, and alcohol consumption (model 2); and, finally, a regression model adjusted for the variables included in model 2 plus menopausal status (women only), low and high density lipoprotein cholesterol, triglycerides, diuretic use, DM2 and family history of DM2 (model 3 ). $P$ values $<0.05$ were considered statistically significant. All statistical procedures were performed using the SPSS software (SPSS version 15.0, Inc.).

\section{Results}

This study included 1276 subjects (640 women, 636 men) with a mean age $54 \pm 9$ (SD) years, with no family history of premature CHD or CVD symptoms. Compared to women, men had a higher prevalence of high blood pressure ( $11.9 \%$ vs $7.3 \%, p=0.006)$, insulin resistance $(61.8 \%$ vs $54.7 \%, p=0.011)$ and metabolic syndrome ( $49.2 \%$ vs $40.9 \%, p=0.003)$. The prevalence of current smoking (25.1\% of men and $18.9 \%$ of women) and type 2 diabetes mellitus (15\% of men and $13.4 \%$ of women) were not significantly different between genders. Two thirds of women $(66.4 \%)$ were postmenopausal. The mean serum magnesium concentration in the whole population was $2.06 \pm 0.17$ (SD) $\mathrm{mg} / \mathrm{dl}$, and was slightly higher in men than in women $(2.07 \pm 0.16$ (SD) $\mathrm{mg} / \mathrm{dl}$ vs $2.06 \pm 0.18$ (SD) $\mathrm{mg} / \mathrm{dl}, p=0.09$ ). The overall prevalence of CAC score $>0$ was $27.2 \%$. (41.5\% of men and $13 \%$ of women, $p<0.001$ ).

Table 1 shows clinical, computed tomography and laboratory characteristics of participants according to serum magnesium quartiles. Systolic blood pressure, fasting glucose, HOMA-IR and $\mathrm{C}$ reactive protein were inversely associated with serum magnesium levels. High serum magnesium levels were also associated with lower prevalence of hypertension, DM2, insulin resistance, metabolic syndrome, and CAC score $>0$. A similar nonsignificant trend was observed for body mass index and fasting insulin levels. In contrast, total and LDLcholesterol and apolipoprotein B were greater with increasing serum magnesium levels. Visceral adipose tissue, triglycerides, and adiponectin were not associated with serum magnesium levels.

Multivariate logistic regression analyses were performed to examine the associations of serum magnesium levels with cardiometabolic risk factors and CAC score $>0$ (Table 2). After adjustment for several confounding 
Table 1 Characteristics of 1276 GEA study participants according to serum magnesium quartiles

\begin{tabular}{|c|c|c|c|c|c|}
\hline & $\mathrm{Q} 1<1.97 \mathrm{mg} / \mathrm{dl}$ & $\mathrm{Q} 2 \geq 1.97$ to $<2.07 \mathrm{mg} / \mathrm{dl}$ & $\mathrm{Q} 3 \geq 2.07$ to $<2.18 \mathrm{mg} / \mathrm{dl}$ & $\mathrm{Q} 4 \geq 2.18 \mathrm{mg} / \mathrm{dl}$ & $P^{*}$ \\
\hline N & 326 & 304 & 338 & 308 & \\
\hline Serum magnesium (mg/dl) & $1.90[1.83-1.94]$ & $2.03[2.00-2.05]$ & $2.11[2.09-2.14]$ & $2.24[2.20-2.29]$ & $<0.001$ \\
\hline Dietary magnesium (mg) & $351[290-410]$ & 344 [292-421] & 356 [289-424] & 358 [293-422] & 0.692 \\
\hline Male (\%) & 50 & 49.3 & 51.2 & 49 & 0.949 \\
\hline Age (years) & $54 \pm 10$ & $53 \pm 10$ & $54 \pm 9$ & $55 \pm 9$ & 0.079 \\
\hline Body mass index $\left(\mathrm{kg} / \mathrm{cm}^{2}\right)$ & $28.8 \pm 4.2$ & $28.4 \pm 4.2$ & $28.0 \pm 4.0$ & $28.1 \pm 3.8$ & 0.056 \\
\hline Visceral adipose tissue $\left(\mathrm{cm}^{2}\right)$ & $157[112-211]$ & 148 [112-190] & 150 [109-194] & 148 [115-193] & 0.196 \\
\hline Systolic blood pressure (mmHg) & 118 [108-130] & 113 [103-125] & 114 [106-123] & 113 [103-123] & $<0.001$ \\
\hline Glucose (mg/dl) & $95[87-125]$ & 91 [85-99] & 89 [83-96] & 89 [84-96] & $<0.001$ \\
\hline Insulin $(\mu \mathrm{U} / \mathrm{ml})$ & $18.1[13.2-24.9]$ & $18.2[12.6-24.7]$ & $16.7[12.4-22.8]$ & $16.4[12.3-22.4]$ & 0.067 \\
\hline HOMA-IR & $4.9[3.0-7.5]$ & $4.2[2.8-5.7]$ & $3.7[2.6-5.4]$ & $3.6[2.6-5.1]$ & $<0.001$ \\
\hline \multicolumn{6}{|l|}{ Cholesterol } \\
\hline Total (mg/dl) & $190 \pm 36$ & $190 \pm 37$ & $193 \pm 37$ & $198 \pm 37^{a, b}$ & 0.015 \\
\hline $\mathrm{LDL}(\mathrm{mg} / \mathrm{dl})$ & $116 \pm 32$ & $117 \pm 33$ & $117 \pm 32$ & $123 \pm 33^{\mathrm{a}, \mathrm{b}, \mathrm{c}}$ & 0.009 \\
\hline $\mathrm{HDL}(\mathrm{mg} / \mathrm{dl})$ & $45.7 \pm 13.2$ & $45.1 \pm 13.3$ & $47.8 \pm 14.1$ & $45.6 \pm 13.0$ & 0.065 \\
\hline Triglycerides (mg/dl) & 148 [114-200] & 152 [113-202] & 145 [106-209] & 153 [116-204] & 0.844 \\
\hline Apolipoprotein B (mg/dl) & $92[74-112]$ & 93 [75-111] & 95 [79-115] & $103[85-122]$ & $<0.001$ \\
\hline Apolipoprotein A (mg/dl) & 133 [114-154] & 131 [111-152] & 134 [117-158] & 135 [117-155] & 0.095 \\
\hline Adiponectin ( $\mu \mathrm{g} / \mathrm{ml})$ & $8.0[4.8-11.8]$ & $7.6[5.0-12.1]$ & $8.1[5.2-13.1]$ & $7.8[5.0-12.2]$ & 0.915 \\
\hline hsCRP (mg/l) & $1.8[0.9-3.6]$ & $1.5[0.8-3.3]$ & $1.4[0.7-2.9]$ & $1.4[0.8-3.0]$ & 0.018 \\
\hline Current smoking (\%) & 21 & 23 & 23 & 21 & 0.765 \\
\hline Physical activity & $7.75[6.88-8.88]$ & $7.88[6.75-8.75]$ & $7.88[7.13-8.75]$ & $7.75[7.00-8.63]$ & 0.256 \\
\hline Menopausal women (\%) & 62 & 62.3 & 64.8 & 76.6 & 0.018 \\
\hline Hypertension (\%) & 14 & 8 & 8 & 8 & 0.009 \\
\hline Type 2 diabetes mellitus (\%) & 34 & 10 & 8 & 5 & $<0.001$ \\
\hline Insulin resistance (\%) & 66 & 63 & 53 & 51 & $<0.001$ \\
\hline Metabolic syndrome (\%) & 54 & 44 & 41 & 41 & 0.003 \\
\hline CAC score >0 (\%) & 35 & 24 & 26 & 24 & 0.002 \\
\hline
\end{tabular}

Values are expressed as mean $\pm S D$, median [IR, interquartile range] or percentages. HOMA-IR Homeostasis model assessment insulin resistance, LDL Low density lipoprotein, $H D L$ High density lipoprotein, $h s C R P$ High sensitive $C$ reactive protein

*for ANOVA, Kruskal-Wallis or Chi square test. $P<0.05$ a versus Q1, bversus Q2, 'versus Q3

Table 2 Association of serum magnesium levels with cardiometabolic risk factors and subclinical atherosclerosis

\begin{tabular}{lllll}
\hline & Q1 & Q2 & Q3 & Q4 \\
\hline Hypertension & & Odds ratio [Cl 95 \%] & Odds ratio [Cl 95 \%] & Odds ratio [Cl 95 \%] \\
Insulin resistance & 1 & $0.52[0.295-0.917]$ & $0.56[0.323-0.961]$ & $0.52[0.294-0.931]$ \\
Metabolic syndrome & 1 & $1.26[0.891-1.940]$ & $0.96[0.632-1.467]$ & $1.02[0.694-1.506]$ \\
Type 2 diabetes mellitus & 1 & $1.04[0.715-1.512]$ & $1.01[0.696-1.467]$ & $1.02[0.964-1.506]$ \\
CAC score >0 & 1 & $0.42[0.199-0.886]$ & $0.34[0.161-0.705]$ & $0.31[0.143-0.672]$ \\
\hline
\end{tabular}

Data are expressed as odds ratios and $95 \%$ confidence interval $(\mathrm{Cl})$ as assessed by multivariate logistic regression analyses. Other covariates included in the multivariable regression model, along with serum magnesium were: age, sex, education, smoking status, elevated abdominal visceral adipose tissue, body mass index, systolic blood pressure, low and high density lipoprotein cholesterol, triglycerides, fasting insulin and glucose, physical activity, alcohol consumption, menopausal status (women only), family history of type 2 diabetes mellitus, type 2 diabetes mellitus and diuretic use 
factors, individuals with the highest serum magnesium levels (fourth quartile) had $48 \%$ lower odds lower odds of hypertension $(p=0.028), 69 \%$ lower odds of DM2 ( $p=$ $0.003)$, and $42 \%$ lower odds of CAC score $>0(p=0.016)$ as compared to those in the lowest quartile.

Associations of a $1 \mathrm{SD}(0.17 \mathrm{mg} / \mathrm{dL})$ increment in serum magnesium levels with hypertension, insulin resistance, metabolic syndrome, and DM2 are described in Table 3. Variables included in the multivariable model were age, sex, education, smoking status, elevated abdominal visceral adipose tissue, body mass index, systolic blood pressure, LDL-C, HDL-C, triglycerides, fasting insulin and glucose, physical activity, alcohol consumption, menopausal status (women only) and diuretic use. Higher serum magnesium was associated with $19 \%$ lower prevalence of hypertension and $38 \%$ lower prevalence of DM2 per each $1 \mathrm{SD}$ increment in magnesium concentration.

In addition, regression models were used to test the association between $\mathrm{CAC}$ and serum magnesium levels as a continuous variable. A $0.17 \mathrm{mg} / \mathrm{dl}$ (1SD) increment in serum magnesium concentration was associated with $16 \%$ lower coronary artery calcification (odds ratio 0.84; $95 \%$ confidence intervals (CI) $0.741-0.953, p=0.007$ ) in the unadjusted model. This association proved to be independent of age, sex, education, smoking status, body mass index, systolic blood pressure, and physical activity (model 1; odds ratio 0.84; CI 0.724-0.964, $p=0.014$ ). A regression model further adjusted for elevated abdominal visceral adipose tissue, fasting insulin and glucose, and alcohol consumption (model 2; odds ratio 0.86; CI 0.737-0.995, $p=0.043$ ) continued to show a significant independent association between serum magnesium concentrations and CAC. Finally, after a full adjustment (model 2 plus menopausal status -women only-, low and high density lipoprotein cholesterol, triglycerides, diuretic use, DM2 and family history of DM2), a $0.17 \mathrm{mg} / \mathrm{dL}$ (1SD) increment in serum magnesium concentration remained significantly associated with $16 \%$ lower

Table 3 Associations of serum magnesium concentrations with coronary risk factors

\begin{tabular}{lll}
\hline & Odds ratio & $P$ \\
\hline Hypertension & $0.81[0.673-0.985]$ & 0.034 \\
Insulin resistance & $0.89[0.763-1.044]$ & 0.155 \\
Metabolic syndrome & $1.03[0.891-1.189]$ & 0.694 \\
Type 2 diabetes mellitus & $0.62[0.489-0.786]$ & $<0.001$ \\
\hline
\end{tabular}

Odds ratios are expressed in terms of per SD $0.17 \mathrm{mg} / \mathrm{dl}$ increase in serum magnesium levels

Multivariate logistic regression analyses adjusted for age, sex, education, smoking status, elevated abdominal visceral adipose tissue, body mass index, systolic blood pressure, low and high density lipoprotein cholesterol, triglycerides, fasting insulin and glucose, physical activity, alcohol consumption, menopausal status (women only) and diuretic use coronary artery calcification (odds ratio $0.84 ; 95 \%$ confidence interval (CI) $0.724-0.986, p=0.033$ ).

\section{Discussion}

We report here an inverse association between serum magnesium levels and the prevalence of CAC score $>0$ in a Mexican-mestizo population with no family history of premature CHD or clinical signs or symptoms of CVD. This association remained significant after adjustment for a range of confounding factors, including age, sex, education, smoking status, visceral adipose tissue, body mass index, systolic blood pressure, low and high density lipoprotein cholesterol, triglycerides, fasting insulin and glucose, physical activity, alcohol consumption, menopausal status (women only), diuretic use, DM2, and family history of DM2. Serum magnesium levels were also independently associated with a lower risk hypertension and DM2. The latter associations are consistent with previous reports showing that both conditions are frequently associated with a magnesium deficient state as assessed by decreased circulating concentrations of serum total or ionized magnesium $[4,9,30,31]$.

In regard to the association of magnesium with subclinical atherosclerosis, only two population-based epidemiologic studies have examined the relation of magnesium intake with coronary artery calcification. The first study was conducted in 5281 MESA (the Multi-Ethnic Study of Atherosclerosis) participants aged 45-84 years and free of clinically apparent CVD, reporting no association between magnesium intake and CAC [16]. The more recent study included 2695 offspring or third generation Framing Heart Study participants free of CVD and reported that higher magnesium intake was associated with lower levels of CAC [15].

Although an association between serum magnesium levels and $\mathrm{CAC}$ has been reported in patients with chronic kidney disease [20], to date, only one crosssectional analysis has examined serum magnesium levels in relation to $\mathrm{CAC}$, in large number of Korean individuals without cardiovascular disease participating in a health examination program [18]. After adjusting for potential confounders, a significant inverse association between $\mathrm{CAC}$ and serum magnesium was observed, which is consistent with the findings of the present study. In agreement with these investigations, two decades ago the Atherosclerosis Risk in Communities Study reported an inverse association between serum magnesium and carotid intima-media thickness (CIMT) [3]. More recently, in a population-based study, Hashimoto et. al. reported that low serum magnesium levels were not only significantly and independently associated with greater CIMT, but also with the presence of atherosclerotic plaques [14]. Increased CIMT is also a marker of atherosclerotic disease, and like $\mathrm{CAC}$, is and 
independent predictor of cardiovascular morbidity and mortality [11, 12]. Collectively, the results of this and other studies $[3,14,15,18]$ suggest independent associations between reduced magnesium dietary intake or low serum magnesium levels with subclinical atherosclerosis defined either as increased CIMT or as coronary artery calcification.

To date, the underlying mechanisms responsible for the associations between serum magnesium and CAC are incompletely understood. The adverse cardiovascular risk profile found in subjects with low levels of serum magnesium (higher prevalence of DM2, hypertension, insulin resistance, and metabolic syndrome) could explain the association. However, in our analysis and in the report of Lee et.al. [18], the associations between low magnesium and coronary artery calcification remained significant after adjustment for these potential confounders. This suggests that additional mechanisms, beyond classic cardiovascular and metabolic risk factors, could be partly responsible. Results from other experimental models support the role of these other mechanisms. Experiments in cultured endothelial cells have demonstrated that magnesium deficiency promotes a proatherogenic phenotype [32]. Moreover, dietary magnesium restriction in animal models resulted in reduced plasma and erythrocyte magnesium levels, which was accompanied by endothelial dysfunction and systemic inflammation, well known factors involved in the atherogenic process. Interestingly, these abnormalities were reverted by magnesium supplementation [33]. These findings are in line with the beneficial effects of magnesium on inflammation and endothelial dysfunction [34], and suggest that this mineral may prevent the onset and progression of atherosclerosis through mechanisms beyond known traditional pathways.

The present study has some limitations. First, the cross-sectional design does not allow to establish causal or temporal relationships between serum magnesium and coronary artery calcification. Second, despite the comprehensive nature of the data which allowed adjustment for multiple risk factors, the possibility of confounding from unknown or unmeasured factors cannot be completely ruled out. Third, our study population solely comprised Mexican-mestizo subjects, and thus our findings may not apply to populations of other ethnic backgrounds.

\section{Conclusion}

The results of this study strongly suggest that lower serum magnesium levels are associated with coronary artery calcification in Mexican subjects free of clinically apparent cardiovascular disease. Confirmation of these results in other populations is required. Additional prospective studies are also needed to determine if hypomagnesaemia predicts the development and progression of coronary atherosclerosis.

\section{Abbreviations}

ALT: Alanine aminotransferase; apo A: Apolipoprotein A; apo

B: Apolipoprotein B; AST: Aspartate amonitransferase; CAC: Coronary artery calcification; CHD: Coronary heart disease; CIMT: Carotid intima-media thickness; CV: Coefficient of variation; CVD: Cardiovascular disease; DM2: Type 2 diabetes mellitus; GEA: Genetics of atherosclerotic disease; HDL-C: High density lipoprotein cholesterol; HOMA-IR: Homeostasis model assessment for insulin resistance; hs-CRP: High sensitive C-reactive protein; L:SAR: Liver to spleen attenuation ratio; LDL-C: Low density lipoprotein cholesterol; MS: Metabolic syndrome; VAT: Visceral adipose tissue.

\section{Competing interests}

The authors declare that they have no competing interests.

\section{Authors' contributions}

RPS and CPR- designed the study, were responsible of the data analysis and extraction, and wrote the manuscript with final comment and approval by all the authors. TVM- has been involved in the critical revision of the manuscript for important intellectual content. GCS, GVA, MTT, NPH, JMRP, AMU, EJG and JGJR- provided data and advice regarding study design. All authors were involved in the drafting of the manuscript. All authors read and approved the final manuscript

\section{Acknowledgements}

This project was supported by the National Council for Science and Technology (CONACYT GRANT: SALUD-2014-1-233727). The authors thank all the staff and participants.

\section{Author details}

${ }^{1}$ Departamento de Endocrinología, Instituto Nacional de Cardiología Ignacio Chávez, Juan Badiano 1, Sección XVI, Mexico City 14080, Mexico.

${ }^{2}$ Departamento de Biología Molecular, Instituto Nacional de Cardiología Ignacio Chávez, Juan Badiano 1, Sección XVI, Mexico City 14080, Mexico. ${ }^{3}$ Instituto de Medicina Genómica, Laboratorio de Genómica de

Enfermedades Cardiovasculares, Periférico Sur 4809, Arenal Tepepan, Mexico City 14610, Mexico.

Received: 5 January 2016 Accepted: 24 February 2016

Published online: 01 March 2016

\section{References}

1. Takaya J, Higashino H, Kobayashi Y. Intracellular magnesium and insulin resistance. Magnes Res. 2004;17:126-36.

2. Suárez A, Pulido N, Casla A, Casanova B, Arrieta FJ, Rovira A. Impaired tyrosine-kinase activity of muscle insulin receptors from hypomagnesaemic rats. Diabetologia. 1995;38:1262-70.

3. Ma J, Folsom AR, Melnick SL, Eckfeldt JH, Sharrett AR, Nabulsi AA, Hutchinson RG, Metcalf PA. Associations of serum and dietary magnesium with cardiovascular disease, hypertension, diabetes, insulin, and carotid arterial wall thickness: the ARIC study. Atherosclerosis Risk in Communities Study. J Clin Epidemiol. 1995;48:927-40.

4. Kao WH, Folsom AR, Nieto FJ, Mo JP, Watson RL, Brancati FL. Serum and dietary magnesium and the risk for type 2 diabetes mellitus: the Atherosclerosis Risk in Communities Study. Arch Intern Med. 1999;159:2151-9.

5. Kim DJ, Xun P, Liu K, Loria C, Yokota K, Jacobs Jr DR, He K. Magnesium intake in relation to systemic inflammation, insulin resistance, and the incidence of diabetes. Diabetes Care. 2010;33:2604-10.

6. Iseri LT, French JH. Magnesium: nature's physiologic calcium blocker. Am Heart J. 1984;108:188-93.

7. Altura BT, Altura BM. Endothelium-dependent relaxation in coronary arteries requires magnesium ions. Br J Pharmacol. 1987;91:449-51.

8. Szabó C, Faragó M, Dóra E. Effect of small changes in extracellular magnesium concentration on the tone of feline mesenteric arteries: involvement of endothelium. Acta Physiol Hung. 1992;79:295-303.

9. Peacock JM, Folsom AR, Arnett DK, Eckfeldt JH, Szklo M. Relationship of serum and dietary magnesium to incident hypertension: the Atherosclerosis Risk in Communities (ARIC) Study. Ann Epidemiol. 1999;9:159-65. 
10. Liao F, Folsom AR, Brancati FL. Is low magnesium concentration a risk factor for coronary heart disease? The Atherosclerosis Risk in Communities (ARIC) Study. Am Heart J. 1998;136:480-90.

11. Simon A, Gariepy J, Chironi G, Megnien JL, Levenson J. Intima-media thickness: a new tool for diagnosis and treatment of cardiovascular risk. J Hypertens. 2002;20:159-69.

12. O'Leary DH, Polak JF, Kronmal RA, Manolio TA, Burke GL, Wolfson Jr SK. Carotid-artery intima and media thickness as a risk factor for myocardial infarction and stroke in older adults. Cardiovascular Health Study Collaborative Research Group. N Engl J Med. 1999;340:14-22.

13. Detrano R, Guerci AD, Carr JJ, Bild DE, Burke G, Folsom AR, Liu K, Shea S, Szklo M, Bluemke DA, O'Leary DH, Tracy R, Watson K, Wong ND, Kronmal RA. Coronary calcium as a predictor of coronary events in four racial or ethnic groups. N Engl J Med. 2008;358:1336-45.

14. Hashimoto T, Hara A, Ohkubo T, Kikuya M, Shintani Y, Metoki H, Inoue R, Asayama K, Kanno A, Nakashita M, Terata S, Obara T, Hirose T, Hoshi H, Totsune K, Satoh H, Imai Y. Serum magnesium, ambulatory blood pressure, and carotid artery alteration: the Ohasama study. Am J Hypertens. 2010;23:1292-8.

15. Hruby A, O'Donnell CJ, Jacques PF, Meigs JB, Hoffmann U, McKeown NM. Magnesium intake is inversely associated with coronary artery calcification: the Framingham Heart Study. JACC Cardiovasc Imaging. 2014;7:59-69.

16. de Oliveira Otto MC, Alonso A, Lee DH, Delclos GL, Jenny NS, Jiang R, Lima JA, Symanski E, Jacobs DR Jr, Nettleton JA. Dietary micronutrient intakes are associated with markers of inflammation but not with markers of subclinical atherosclerosis. J Nutr. 2011;141:1508-15.

17. Massy ZA, Drüeke TB. Magnesium and outcomes in patients with chronic kidney disease: focus on vascular calcification, atherosclerosis and survival. Clin Kidney J. 2012;5 Suppl 1:i52-61.

18. Lee $S Y$, Hyun YY, Lee KB, Kim H. Low serum magnesium is associated with coronary artery calcification in a Korean population at low risk for cardiovascular disease. Nutr Metab Cardiovasc Dis. 2015;25:10561061.

19. McClelland RL, Chung H, Detrano R, Post W, Kronmal RA. Distribution of coronary artery calcium by race, gender, and age: results from the Multi-Ethnic Study of Atherosclerosis (MESA). Circulation. 2006;113:30-7.

20. Bild DE, Detrano R, Peterson D, Guerci A, Liu K, Shahar E, Ouyang P, Jackson $S$, Saad MF. Ethnic differences in coronary calcification: the Multi-Ethnic Study of Atherosclerosis (MESA). Circulation. 2005;111:1313-20.

21. Villarreal-Molina T, Posadas-Romero C, Romero-Hidalgo $S$, Antúnez-Argüelles $E$, Bautista-Grande A, Vargas-Alarcón G, Kimura-Hayama E, Canizales-Quinteros S, Juárez-Rojas JG, Posadas-Sánchez R, Cardoso-Saldaña G, Medina-Urrutia A, González-Salazar Mdel C, Martínez-Alvarado R, Jorge-Galarza E, Carnevale A. The ABCA1 gene R230C variant is associated with decreased risk of premature coronary artery disease: the genetics of atherosclerotic disease (GEA) study. PLoS One. 2012:7, e49285.

22. Grundy SM, Cleeman JI, Daniels SR, Donato KA, Eckel RH, Franklin BA, Gordon DJ, Krauss RM, Savage PJ, Smith SC Jr, Spertus JA, Costa F, American Heart Association; National Heart, Lung, and Blood Institute. Diagnosis and management of the metabolic syndrome: an American Heart Association/ National Heart, Lung, and Blood Institute Scientific Statement. Circulation. 2005:112:2735-52.

23. Sánchez-Castillo CP, Velazquez-Monroy O, Bever A, et al. Anthropometry Cutoff points for predicting chronic disease in the Mexican National Health Survey. Obes Res. 2003;11:442-51.

24. American Diabetes Association. Diagnosis and classification of diabetes mellitus. Diabetes Care. 2009;32 Suppl 1:S62-7.

25. DeLong DM, DeLong ER, Wood PD, Lippel K, Rifkind BM. A comparison of methods for the estimation of plasma low- and very low-density lipoprotein cholesterol. The Lipid Research Clinics Prevalence Study. JAMA. 1986;256:2372-7.

26. Kvist H, Chowdhury B, Grangård U, Tylén U, Sjöström L. Total and visceral adipose-tissue volumes derived from measurements with computed tomography in adult men and women: predictive equations. Am J Clin Nutr. 1988;48:1351-61

27. Longo R, Ricci C, Masutti F, Vidimari R, Crocé LS, Bercich L, Tiribelli C, Dalla Palma L. Fatty infiltration of the liver. Quantification by $1 \mathrm{H}$ localized magnetic resonance spectroscopy and comparison with computed tomography. Invest Radiol. 1993;28:297-302

28. Mautner GC, Mautner SL, Froehlich J, Feuerstein IM, Proschan MA, Roberts WC, Doppman JL. Coronary artery calcification: assessment with electron beam CT and histomorphometric correlation. Radiology. 1994;192:619-23.
29. McKimmie RL, Daniel KR, Carr JJ, Bowden DW, Freedman Bl, Register TC, Hsu FC, Lohman KK, Weinberg RB, Wagenknecht LE. Hepatic steatosis and subclinical cardiovascular disease in a cohort enriched for type 2 diabetes: the Diabetes Heart Study. Am J Gastroenterol. 2008;103:3029-35.

30. Barbagallo M, Dominguez $\amalg$. Magnesium metabolism in type 2 diabetes mellitus, metabolic syndrome and insulin resistance. Arch Biochem Biophys. 2007;458:40-7.

31. Corica F, Corsonello A, lentile R, Cucinotta D, Di Benedetto A, Perticone F, Dominguez $\sqcup$, Barbagallo M. Serum ionized magnesium levels in relation to metabolic syndrome in type 2 diabetic patients. J Am Coll Nutr. 2006;25:210-5.

32. Ferrè $\mathrm{S}$, Baldoli E, Leidi M, Maier JA. Magnesium deficiency promotes a pro-atherogenic phenotype in cultured human endothelial cells via activation of NFkB. Biochim Biophys Acta. 1802;2010:952-8.

33. Kharitonova M, lezhitsa I, Zheltova A, Ozerov A, Spasov A, Skalny A. Comparative angioprotective effects of magnesium compounds. J Trace Elem Med Biol. 2015;29:227-34

34. Song Y, Li TY, van Dam RM, Manson JE, Hu FB. Magnesium intake and plasma concentrations of markers of systemic inflammation and endothelial dysfunction in women. Am J Clin Nutr. 2007:85:1068-74.

\section{Submit your next manuscript to BioMed Central and we will help you at every step:}

- We accept pre-submission inquiries

- Our selector tool helps you to find the most relevant journal

- We provide round the clock customer support

- Convenient online submission

- Thorough peer review

- Inclusion in PubMed and all major indexing services

- Maximum visibility for your research

Submit your manuscript at www.biomedcentral.com/submit
) Biomed Central 